\title{
NMDA receptor activation inhibits the protective effect of BM-MSCs on bleomycin-induced lung epithelial cell damage by inhibiting ERK signaling and the paracrine factor HGF
}

\author{
XIANGPING PENG ${ }^{1,2^{*}}$, XIAOHONG LI I $^{1,3^{*}}, \mathrm{CHEN} \mathrm{LI}^{4}$, SHAOJIE YUE $^{5}$, YANHONG HUANG ${ }^{1}$, PU HUANG $^{1}$, \\ HAIPENG CHENG ${ }^{1}$, YAN ZHOU ${ }^{1}$, YITING TANG ${ }^{1}$, WEI LIU $^{6}$, DANDAN FENG ${ }^{1 * *}$ and ZIQIANG LUO ${ }^{1 * *}$ \\ ${ }^{1}$ Department of Physiology, Xiangya School of Medicine, Central South University, Changsha, Hunan 410078; \\ ${ }^{2}$ Department of Physiology, Medical College of Jishou University, Jishou, Hunan 416000; ${ }^{3}$ Department of Pathology, \\ The Second Xiangya Hospital, Central South University, Changsha, Hunan 410011; ${ }^{4}$ Department of Physiology, \\ Changzhi Medical College, Changzhi, Shanxi 046000; ${ }^{5}$ Department of Neonatology, Xiangya Hospital; ${ }^{6}$ Department of \\ Community Nursing, Xiangya Nursing School, Central South University, Changsha, Hunan 410078, P.R. China
}

Received November 14, 2018; Accepted May 7, 2019

DOI: $10.3892 / \mathrm{ijmm} .2019 .4195$

\begin{abstract}
Endoplasmic reticulum (ER) stress in alveolar epithelial cells (AECs) is associated with the pathogenesis of pulmonary fibrosis. Bone marrow-derived mesenchymal stromal cells (BM-MSCs) can exert protective effects on ER-stressed AECs via paracrine signaling. In the present study, mouse lung epithelial (MLE)-12 cells were directly stimulated with various concentrations of bleomycin (BLM). MLE-12 cell apoptosis was detected by flow cytometry, and Ki67 expression was detected by immunofluorescence to reflect cell proliferation. The results revealed that BLM increased the protein expression levels of X-box binding protein 1 and immunoglobulin heavy chain-binding protein, thus inducing ER stress, and caused cell dysfunction by inhibiting proliferation and promoting apoptosis. In addition, MSC-derived conditioned medium (MSC-CM) protected MLE-12 cells from BLM-induced injury, by reducing ER stress, promoting cell proliferation and inhibiting cell apoptosis. Our previous studies reported that N-methyl-D-aspartate (NMDA) receptor activation partially inhibits the antifibrotic effect of BM-MSCs on BLM-induced pulmonary fibrosis through downregulating the paracrine factor hepatocyte growth factor (HGF). In the present study, the synthesis and secretion of HGF were
\end{abstract}

Correspondence to: Professor Ziqiang Luo or Dr Dandan Feng, Department of Physiology, Xiangya School of Medicine, Central South University, 88 Xiangya Road, Changsha, Hunan 410078, P.R. China

E-mail: luoziqiang@csu.edu.cn

E-mail: fdd5964@163.com

\section{${ }^{* * * *}$ Contributed equally}

Key words: bone marrow-derived mesenchymal stromal cell, alveolar epithelial cell, N-methyl-D-aspartate receptor, hepatocyte growth factor, extracellular signal-regulated kinase detected by western blotting and ELISA, respectively. Results further demonstrated that NMDA inhibited the synthesis and secretion of HGF in BM-MSCs, and NMDA-preconditioned MSC-CM had no protective effects on BLM-induced injury in MLE-12 cells. In addition, activation of the NMDA receptor decreased the phosphorylation levels of extracellular signal-regulated kinase (ERK)1/2 in BM-MSCs. Using Honokiol and FR180204, the activator and inhibitor of ERK1/2, respectively, it was then revealed that Honokiol partially eliminated the decrease in HGF expression, whereas FR180204 further promoted the reduction in HGF caused by NMDA. Collectively, these findings suggested that NMDA receptor activation may downregulate HGF by inhibiting ERK signaling in BM-MSCs, thus weakening their protective effects on BLM-induced lung epithelial cell damage.

\section{Introduction}

Idiopathic pulmonary fibrosis (IPF) is the common end stage of numerous interstitial diseases with a median survival period of 3-5 years (1). It is characterized by an excessive deposition of extracellular matrix components, leading to structural destruction of the lung architecture (2). Dysfunction of alveolar epithelium, particularly type II alveolar epithelial cells (AECs), serves a key role in this disease (3). Following repetitive or ongoing injury to the alveolar epithelium, the repair process cannot complete normal re-epithelialization, resulting in alveolar-capillary damage. This process induces cytokine production, fibroblast surface expression of cytokine receptors, cytokine accumulation to the injured site and proliferation (4). Numerous studies have demonstrated that endoplasmic reticulum (ER) stress in type II AECs is a pathological mechanism of pulmonary fibrosis (5-8).

The ER is an important intracellular organelle that maintains cell activity and normal cellular function, which has an important role in controlling calcium ion $\left(\mathrm{Ca}^{2+}\right)$ homeostasis, and synthesis, folding and maturation of most secreted and transmembrane proteins (9). In the ER, nascent proteins are 
folded with the assistance of ER chaperones. ER stress occurs if the folding of nascent proteins in the ER is disrupted by homeostatic alterations in the ER lumen. When unfolded and/or misfolded proteins accumulate in the ER lumen, the eukaryotic cells activate a signal transduction cascade response, termed the unfolded protein response (UPR) $(9,10)$. Lawson et al reported that the induction of ER stress in the alveolar epithelium of fibrotic lungs can lead to type II AEC dysfunction and contribute to the pathogenesis of this disease (5).

Mesenchymal stromal cells (MSCs) have generated interest as a potential cell source for cell-based therapeutic strategies for tissue repair and regenerative diseases, due to their intrinsic ability to self renew, differentiate into functional cells and secrete various paracrine factors (11). Preclinical studies and clinical trials on MSC-based therapy as a potential treatment for lung injury and fibrosis have been performed $(12,13)$. The administration of exogenous MSCs has achieved satisfactory effects in ameliorating lung inflammation and fibrosis in animal models and clinical trials (14). Notably, the strong paracrine activity of MSCs is considered the principal mechanism underlying their effects on maintaining function in damaged organs (1). The hepatocyte growth factor (HGF) serves an important role in protecting vascular permeability and is an important, soluble paracrine factor responsible for the beneficial effects of MSCs (15). The antifibrotic effect of MSCs is partly dependent on the endogenous secretion of HGF (16).

The N-methyl-D-aspartate (NMDA) receptor is a subtype of the ionotropic glutamate receptor family that is highly permeable to $\mathrm{Ca}^{2+}(17)$. The NMDA receptor has a crucial role in numerous physiological processes, including long-term potentiation and synaptic plasticity. However, NMDA receptor activation-mediated glutamate toxicity can cause nerve cell apoptosis, and the dysfunction of this receptor is involved in several neural diseases (18). Recently, our previous study demonstrated that NMDA receptor expression is present in bone marrow-derived MSCs (BM-MSCs) and NMDA receptor activation induces BM-MSC dysfunction in vitro, thus abolishing the therapeutic effects of BM-MSC transplantation on bleomycin (BLM)-induced pulmonary fibrosis in vivo (19). NMDA receptor activation eliminates the inhibitory effects of BM-MSCs on epithelial-mesenchymal transition (EMT) and fibroblast activation by reducing HGF secretion (19). In the present study, it was hypothesized that reduced HGF secretion caused by NMDA receptor activation may impair the protective effects of BM-MSCs on BLM-induced lung epithelial cell damage, and the underlying mechanism may be associated with inhibition of the extracellular signal-regulated kinase (ERK) signaling pathway.

\section{Materials and methods}

Experimental animals. A total of 20 female C57BL/6 mice (age, 4 weeks; weight, 10-12 g) were purchased from Hunan Silaike Jingda Laboratory Animal Co., Ltd. (Changsha, China). Mice were maintained under a 12-h light/dark cycle with free access to standard food and water. The animal room was maintained at a temperature of $22-24^{\circ} \mathrm{C}$ and relative humidity of $45-60 \%$. This study was approved by the Ethics Committee of the Institute of Clinical Pharmacology at Central South University (Changsha, China). Prior to surgery, mice were anesthetized with $5 \%$ chloral hydrate $(400 \mathrm{mg} / \mathrm{kg}$, i.p.), and necessary efforts were made to minimize suffering.

BM-MSC isolation and culture. Bone marrow aspirates were obtained from the femur and tibia of 4-week-old C57BL/6 mice under deep anesthesia. Mouse BM-MSCs were isolated, cultured and characterized as previously reported (20). Briefly, bone marrow aspirates were flushed with Dulbecco's modified Eagle medium/nutrient mixture F-12 (DMEM/F12; HyClone; GE Healthcare Life Sciences, Logan, UT, USA) containing 10\% fetal bovine serum (FBS; Gibco; Thermo Fisher Scientific, Inc., Waltham, MA, USA), $100 \mathrm{U} / \mathrm{ml}$ penicillin, $100 \mu \mathrm{g} / \mathrm{ml}$ streptomycin and $2 \mathrm{mM}$ L-glutamine (Gibco; Thermo Fisher Scientific, Inc.) in a $60-\mathrm{mm}$ dish. The cell solution was dispersed by pipetting the solution up and down to create a single-cell suspension, which was transferred to a $25-\mathrm{cm}^{2}$ cell culture flask. Subsequently, the cells were cultured at $37^{\circ} \mathrm{C}$ in a humidified incubator containing $5 \% \mathrm{CO}_{2}$. After $48 \mathrm{~h}$, the media were replaced with fresh complete culture medium after gently removing the nonadherent cells with PBS. Mouse BM-MSCs were passaged five times and were characterized by their adipogenic, osteogenic and chondrogenic differentiation potential, and by flow cytometric analysis of surface markers. The cells were used at early passages ( $<6$ passages) for all experiments.

Flow cytometry. At passage 5 (P5), BM-MSCs were detached with $0.25 \%$ trypsin/ $0.02 \%$ EDTA for $1 \mathrm{~min}$, washed with PBS and pelleted by centrifugation for $5 \mathrm{~min}$ at $250 \mathrm{x}$ g. Subsequently, $1 \times 10^{5} \mathrm{BM}-\mathrm{MSCs}$ were resuspended in $1 \mathrm{ml} 0.1 \%$ bovine serum albumin (BSA; cat. no. ST023; Beyotime Institute of Biotechnology, Shanghai, China) in PBS, followed by immunodepletion at $4^{\circ} \mathrm{C}$ for $30 \mathrm{~min}$. The cells were incubated with anti-mouse cluster of differentiation (CD)29, CD44, CD90.2, CD31, CD34 and CD117 (cat. no. MUXMX-09011; Cyagen Biosciences, Inc., Guangzhou, China) at a concentration of $2 \mu \mathrm{g} / \mathrm{ml}$ at $4^{\circ} \mathrm{C}$ for $30 \mathrm{~min}$, according to the manufacturer's protocol. Cells incubated with corresponding rat immunoglobulin $\mathrm{G}(\mathrm{IgG})$ and Armenian hamster IgG isotype control antibody (cat. no. MUXMX-09011; Cyagen Biosciences, Inc.) at a concentration of $2 \mu \mathrm{g} / \mathrm{ml}$ served as negative controls. After $30 \mathrm{~min}$, to remove unbound antibodies, cells were washed twice with $1 \mathrm{ml} 0.1 \%$ BSA. Subsequently, the cells were incubated with fluorescein isothiocyanate-conjugated goat anti-rat/hamster IgG secondary antibody (cat. no. MUXMX-09011; Cyagen Biosciences, Inc.) at a concentration of $2 \mu \mathrm{g} / \mathrm{ml}$ at $4^{\circ} \mathrm{C}$ in the dark for $30 \mathrm{~min}$, followed by two washes with $1 \mathrm{ml} \mathrm{0.1 \%} \mathrm{BSA.}$ The cell pellets were resuspended in $400 \mu \mathrm{l}$ PBS and examined by flow cytometry (BD Biosciences, Franklin Lakes, NJ, USA) with 5,000 events being recorded for each condition. The results were analyzed using FlowJo software version 7.2.5 (FlowJo LLC, Ashland, OR, USA) to create the histograms.

Differentiation assay. For adipogenic differentiation, $2 \times 10^{5} \mathrm{P} 5$ BM-MSCs were seeded into each well of a 6-well plate and cultured; every 2-3 days the complete medium was replaced until a confluent cell layer was formed. Subsequently, when the cell confluence reached $100 \%$, the cells were stimulated to 
differentiate into the adipogenic lineage by submitting them to three cycles of alternating culture in adipogenic induction medium (cat. no. MUBMX-90031; Cyagen Biosciences, Inc.) and adipogenic maintenance medium (Cyagen Biosciences, Inc.), according to the manufacturer's protocols. At the end of the three cycles, cells were grown for another 7 days in adipogenic maintenance medium. The adipogenic induction medium comprises $87.5 \%$ induction differentiation basal medium, $10 \%$ FBS, $0.2 \%$ insulin (recombinant), $1 \%$ L-glutamine, $0.1 \%$ rosiglitazone, $0.1 \%$ dexamethasone, $0.1 \%$ IBMX and $1 \%$ penicillin/streptomycin. The adipogenic maintenance medium comprises $87.8 \%$ maintenance differentiation basal medium, $10 \%$ FBS, $0.2 \%$ insulin, $1 \%$ L-glutamine and $1 \%$ penicillin/streptomycin. To visualize adipocytes, cells were stained with Oil Red O (Cyagen Biosciences, Inc.). After adipogenic differentiation, cells were washed twice with PBS, $2 \mathrm{ml} \mathrm{4 \%} \mathrm{neutral} \mathrm{formaldehyde} \mathrm{solution} \mathrm{was} \mathrm{added} \mathrm{and} \mathrm{the}$ cells were fixed for $30 \mathrm{~min}$ at room temperature. Subsequently, cells were washed twice with PBS and stained with $1 \mathrm{ml}$ Oil Red O dye working solution (60\% stock solution) for $30 \mathrm{~min}$ at room temperature. Finally, cells were washed twice with PBS and images were captured under a light microscope.

Osteogenic differentiation was induced by exposing $3 \times 10^{4}$ P5 BM-MSCs to osteogenic induction medium (cat. no. MUBMX-90021; Cyagen Biosciences, Inc.) in each well of a 6-well plate. The medium was changed every 3 days, according to the manufacturer's protocol. The osteogenic induction medium contains $10 \% \mathrm{FBS}, 0.01 \%$ dexamethasone, $1 \%$ L-glutamine, $0.2 \%$ ascorbate, $1 \%$ penicillin/streptomycin and $1 \% \beta$-glycerophosphate. To verify osteogenic differentiation, Alizarin Red S was used to stain calcium deposits. After osteogenic differentiation, cells were washed twice with PBS, $2 \mathrm{ml}$ of $4 \%$ neutral formaldehyde solution was added and the cells were fixed for $30 \mathrm{~min}$ at room temperature. Subsequently, cells were washed twice with PBS and stained with $1 \mathrm{ml}$ Alizarin Red dye solution for $5 \mathrm{~min}$ at room temperature. Finally, cells were washed twice with PBS and images were captured under a light microscope.

To induce chondrogenic differentiation, $2.5 \times 10^{5} \mathrm{P} 5$ BM-MSCs were washed twice in incomplete chondrogenesis induction medium (cat. no. MUBMX-9004; Cyagen Biosciences, Inc.). Cells were then sedimented by centrifugation at $150 \mathrm{x}$ g for $5 \mathrm{~min}$ and $0.5 \mathrm{ml}$ complete chondrogenesis induction medium (Cyagen Biosciences, Inc.) was added to the cell pellet. Incomplete chondrogenesis induction medium contains $0.01 \%$ dexamethasone, $0.3 \%$ ascorbate, $1 \%$ ITS + supplement, $1 \%$ penicillin/streptomycin, $0.1 \%$ sodium pyruvate, $0.1 \%$ proline and $1 \% \mathrm{~L}$-glutamine. Complete medium was produced by adding $10 \mu \mathrm{l}$ transforming growth factor- $\beta 3$ (Lonza Group, Ltd., Basel, Switzerland) to $1 \mathrm{ml}$ incomplete medium. The medium was changed every 3-4 days. After 21 days of culture, the cells were detected by Alcian blue staining. After chondrogenic differentiation, the cartilage spheres were subjected to $10 \%$ formalin fixation for $24 \mathrm{~h}$ at room temperature and were embedded in paraffin. Paraffin-embedded sections $(5 \mu \mathrm{m})$ were dewaxed and dehydrated, and stained with Alcian blue dye solution for $30 \mathrm{~min}$ at room temperature. Subsequently, sections were washed with tap water for $2 \mathrm{~min}$ and rinsed with distilled water once. Finally, Alcian blue staining was observed under a light microscope and images were captured.
Cell viability assay. Cell Counting kit-8 (CCK-8; Beyotime Institute of Biotechnology) was used to measure cell viability. To evaluate the effects of $\operatorname{BLM}(0,0.01,0.1,1,10$ and $100 \mu \mathrm{g} / \mathrm{ml}$; Sigma-Aldrich; Merck KGaA, Darmstadt, Germany) on mouse lung epithelial (MLE)-12 cell (cat. no. CRL-2110; American Type Culture Collection, Manassas, VA, USA) viability, $2 \times 10^{3}$ cells in $100 \mu \mathrm{l}$ DMEM/F12 supplemented with $10 \%$ FBS were seeded into flat-bottomed 96 -well culture plates at $37^{\circ} \mathrm{C}$ in a humidified incubator containing $5 \% \mathrm{CO}_{2}$. Once cell confluence reached $30-40 \%$, the growth media were supplemented with the indicated concentrations of BLM for $24 \mathrm{~h}$. Subsequently, cell viability was evaluated using the CCK-8 assay, and the absorbance of resulting formazan was measured at $450 \mathrm{~nm}$ using a microplate reader (Thermo Fisher Scientific, Inc.), according to the manufacturer's protocol.

Lactate dehydrogenase ( $L D H$ ) activity assay. MLE-12 cells were plated in 96 -well plates $\left(5 \times 10^{3} /\right.$ well) and were incubated with medium containing various concentrations of BLM $(0,0.01,0.1,1,10$ and $100 \mu \mathrm{g} / \mathrm{ml})$ for $24 \mathrm{~h}$. The cell medium was collected for measurement of LDH activity. LDH activity was detected using the LDH assay kit (cat. no. A020-2; Nanjing Jiancheng Bioengineering Institute, Nanjing, China), according to the manufacturer's protocol. The optical density was measured at $450 \mathrm{~nm}$ using a microplate reader (Thermo Fisher Scientific, Inc.).

Generation of MSC-derived conditioned medium (MSC-CM). BM-MSCs $\left(1 \times 10^{5} /\right.$ well) were seeded in 6-well culture plates and allowed to adhere for $6 \mathrm{~h}$. Subsequently, they were washed with PBS and 3 mM NMDA (cat. no. M3262; Sigma-Aldrich; Merck KGaA) was used to treat BM-MSCs for $24 \mathrm{~h}$ at $37^{\circ} \mathrm{C}$ in a humidified incubator containing $5 \% \mathrm{CO}_{2}$. Finally, MSC-CM was collected and centrifuged at $250 \mathrm{x}$ g for $5 \mathrm{~min}$. MSC-CM was immediately used for subsequent experiments.

Co-culture of MLE-12 cells with MSC-CM. Following treatment with $1 \mu \mathrm{g} / \mathrm{ml}$ BLM for $24 \mathrm{~h}$, MLE-12 cells (70\% confluence) were then incubated with a mixture of DMEM/F12 culture media and MSC-CM or NMDA-preconditioned MSC-CM (1:1) for $24 \mathrm{~h}$ at $37^{\circ} \mathrm{C}$ in a humidified incubator containing $5 \%$ $\mathrm{CO}_{2}$.

Cell apoptosis analysis. Briefly, $1 \times 10^{5}$ MLE-12 cells were treated with $1 \mu \mathrm{g} / \mathrm{ml}$ BLM for $24 \mathrm{~h}$. BLM-treated MLE-12 cells were then co-cultured with normal or $3 \mathrm{mM}$ NMDA-preconditioned MSC-CM for $24 \mathrm{~h}$. In addition, $10 \mathrm{ng} / \mathrm{ml}$ HGF was simultaneously used to treat MLE-12 cells. Cell apoptosis was measured by flow cytometry using the Annexin $\mathrm{V}$ and propidium iodide (PI) double staining kit (cat. no. CA001; Signalway Antibody LLC, College Park, MD, USA), according to the manufacturer's protocol. The data were analyzed using FlowJo 7.6 software (FlowJo LLC). The percentage of early-phase apoptotic cells (lower right quadrant, Annexin $\mathrm{V}^{+} / \mathrm{PI}^{-}$) and late-phase apoptotic cells (upper right quadrant, Annexin $\mathrm{V}^{+} / \mathrm{PI}^{+}$) was determined and graphs were generated for comparison.

Western blotting. MLE-12 cells were treated with various concentrations of $\operatorname{BLM}(0,0.01,0.1,1,10$ and $100 \mu \mathrm{g} / \mathrm{ml})$ for 
$24 \mathrm{~h}$ at $37^{\circ} \mathrm{C}$. BM-MSCs were treated with 3 or $10 \mathrm{mM}$ NMDA for $24 \mathrm{~h}$, with or without $50 \mu \mathrm{M}$ MK801 (cat. no. SML0304; Sigma-Aldrich; Merck KGaA) pretreatment for $30 \mathrm{~min}$ prior to $10 \mathrm{mM}$ NMDA treatment. In addition, BM-MSCs were treated with $10 \mu \mathrm{M}$ Honokiol (cat. no. S2310; Selleck Chemicals, Houston, TX, USA) or FR180204 (cat. no. S7524; Selleck Chemicals), which are the activator and inhibitor of ERK1/2, respectively for $30 \mathrm{~min}$ prior to $3 \mathrm{mM}$ NMDA treatment for $24 \mathrm{~h}$. Total protein was extracted from cells using radioimmunoprecipitation assay buffer (Beyotime Institute of Biotechnology), containing protease inhibitor (cat. no. 04693159001; Roche Diagnostics GmbH, Mannheim, Germany) and PhosSTOPтм (cat. no. 04906845001; Roche Diagnostics $\mathrm{GmbH}$ ), according to the manufacturer's protocol. Whole protein concentration for loading was estimated using the Bradford assay. Total protein (30-50 $\mu \mathrm{g})$ was separated by 8-10\% SDS-PAGE and transferred onto polyvinylidene fluoride membranes (EMD Millipore, Bedford, MA, USA). After blocking with $5 \%$ non-fat milk for $2 \mathrm{~h}$, the membranes were incubated overnight at $4^{\circ} \mathrm{C}$ with anti-XBP1 (cat. no. 83418; 1:1,000; Cell Signaling Technology, Inc., Danvers, MA, USA), anti-Bip (cat. no. 3183; 1:1,000; Cell Signaling Technology, Inc.), anti-HGF (cat. no. PB0298; 1:250; Wuhan Boster Biological Technology, Ltd., Wuhan, China), anti-ERK1/2 (cat. no. 4695; 1:1,000; Cell Signaling Technology, Inc.), anti-phosphorylated-ERK1/2 (cat. no. 9101; 1:1,000; Cell Signaling Technology, Inc.) and anti- $\beta$-actin (cat. no. A1978; 1:1,000; Sigma-Aldrich; Merck KGaA) antibodies. The corresponding horseradish peroxidase (HRP)-conjugated goat anti-rabbit IgG (cat. no. AP132; 1:2,500; Sigma-Aldrich; Merck $\mathrm{KGaA}$ ) and HRP-conjugated goat anti-mouse IgG (cat. no. AP124; 1:2,500; Sigma-Aldrich; Merck KGaA) secondary antibodies were applied to the membranes for $2 \mathrm{~h}$ at room temperature. Subsequently, enhanced chemiluminescence reagents (EMD Millipore) were used to detect the targeted antigens. The abundance of targeted proteins was analyzed using the Quantity One Imaging Analysis Program version 3.0 (Bio-Rad Laboratories, Inc., Hercules, CA, USA). The relative protein expression levels were measured by determining the ratio of the targeted antigen to $\beta$-actin. All experiments were performed at least in triplicate.

ELISA. BM-MSCs were treated with 3 and 10 mM NMDA for $24 \mathrm{~h}$ at $37^{\circ} \mathrm{C}$, with or without pretreatment with $50 \mu \mathrm{M}$ MK801 for $30 \mathrm{~min}$ prior to $10 \mathrm{mM}$ NMDA treatment. In addition, BM-MSCs were treated with $10 \mu$ M Honokiol or FR180204 for $30 \mathrm{~min}$ prior to $3 \mathrm{mM}$ NMDA treatment for $24 \mathrm{~h}$. A commercially available ELISA kit was used to evaluate the levels of HGF (cat. no. MHG00; R\&D Systems, Inc., Minneapolis, MN, USA) in the cell supernatant according to the manufacturer's protocol.

Immunofluorescence. MLE-12 cells $\left(1 \times 10^{5}\right)$ were treated with $1 \mu \mathrm{g} / \mathrm{ml} \mathrm{BLM}$ for $24 \mathrm{~h}$ at $37^{\circ} \mathrm{C}$. BLM $(1 \mu \mathrm{g} / \mathrm{ml})$-treated MLE-12 cells were then co-cultured with normal or $3 \mathrm{mM}$ NMDA-preconditioned MSC-CM for $24 \mathrm{~h}$. In addition, $10 \mathrm{ng} / \mathrm{ml} \mathrm{HGF}$ was simultaneously used to treat MLE-12 cells. For cell staining, treated MLE-12 cells were fixed in $4 \%$ paraformaldehyde for $20 \mathrm{~min}$ at room temperature. The samples were washed three times with PBS, followed by incubation with $0.2 \%$ Triton $\mathrm{X}-100$ for $20 \mathrm{~min}$ at room temperature. After washing each sample three times with PBS for $5 \mathrm{~min}$ and pre-incubating with $5 \%$ BSA for $1 \mathrm{~h}$ at room temperature, the samples were incubated with anti-surfactant protein C (pro-SP-C; cat. no. ab170699; 1:200; Abcam, Cambridge, MA, USA) and anti-Ki67 (cat. no. 9129; 1:100; Cell Signaling Technology, Inc.) primary antibodies at $4^{\circ} \mathrm{C}$ overnight. After washing each sample three times with PBS for $10 \mathrm{~min}$, they were incubated with $\mathrm{Cy} 3$-conjugated goat anti-rabbit IgG (cat. no. SA00009-2; 1:50; ProteinTech Group, Inc., Chicago, IL, USA) for $1 \mathrm{~h}$ at room temperature. After three additional washes for $10 \mathrm{~min}$ each with PBS, the nuclei were counterstained with $5 \mu \mathrm{g} / \mathrm{ml}$ DAPI (Beyotime Institute of Biotechnology) for $5 \mathrm{~min}$ at room temperature and then mounted for analysis under a fluorescence microscope (Nikon Corporation, Tokyo, Japan). The total cell numbers and Ki67-positive cell numbers were counted in three images. The percentages of Ki67-positive cells were then calculated.

Recombinant HGF treatment. BLM-stimulated MLE-12 cells were treated with $10 \mathrm{ng} / \mathrm{ml}$ recombinant HGF (R\&D Systems, Inc.) for $24 \mathrm{~h}$ at $37^{\circ} \mathrm{C}$ in a humidified incubator containing $5 \% \mathrm{CO}_{2}$. Subsequently, cells were collected for Ki67 detection by immunofluorescence staining, apoptosis analysis by flow cytometry, and XBP1 and Bip protein expression detection by western blotting.

Data presentation and statistical analysis. Data are presented as the means \pm standard error of the mean from at least three independent experiments. Student's t-test (two-tailed, unpaired) was used to analyze two groups. One-way analysis of variance followed by Tukey's or Dunnett's post hoc tests was used to analyze $\geq 3$ groups. Statistical analyses were performed using SPSS version 16.0 (SPSS, Inc., Chicago, IL, USA). P $\leq 0.05$ was considered to indicate a statistically significant difference.

\section{Results}

Identification of primary BM-MSCs. The detection of surface markers and differentiation potential is very important for confirming the characterization of primary MSCs. MSCs were isolated from the bone marrow of mice and cultured as previously described (20). BM-MSCs were phenotypically identified by their typical fibroblast-like appearance (Fig. 1A-C). The differentiation abilities of BM-MSCs were tested at P5. When cultured in adipogenic, osteogenic and chondrogenic media, BM-MSCs were able to differentiate exclusively into adipocytes, osteoblasts, and chondrocytes, as determined by Oil Red O, Alizarin Red S and Alcian blue staining, respectively (Fig. 1D-F). BM-MSCs were further analyzed for surface antigens. The results revealed that BM-MSCs were strongly positive for CD90.2, CD29 and CD44 (Fig. 1G-I), but were negative for CD31, CD34 and CD117 (Fig. 1J-L). The cultured BM-MSCs displayed normal immunophenotypic characteristics and differentiation potential. These results indicated that the cells conformed to the minimal criteria to be identified as MSCs in vitro (21).

BLM induces ER stress in MLE-12 cells, inhibits their viability and promotes cell apoptosis. Intratracheal injection of BLM 
A

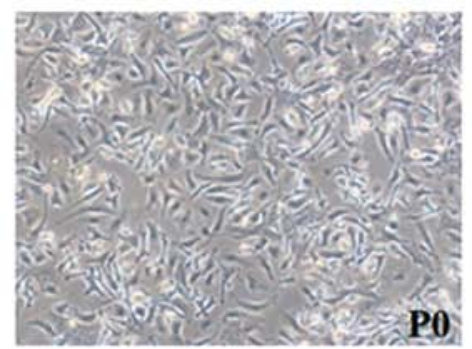

D

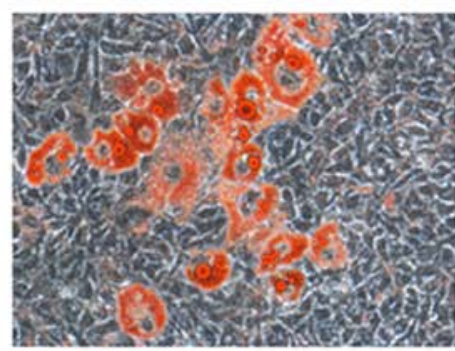

G
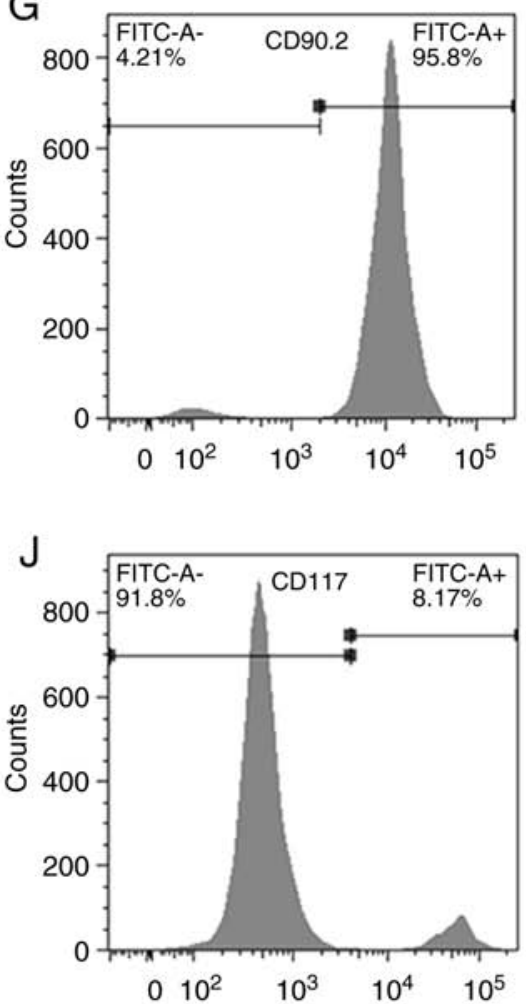

B

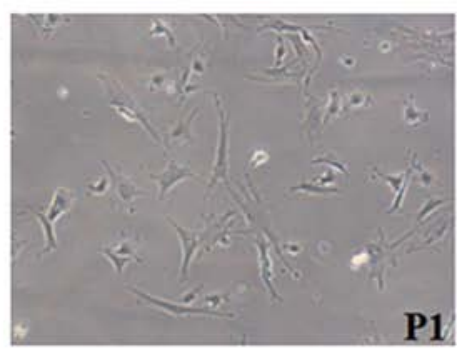

$\mathrm{E}$

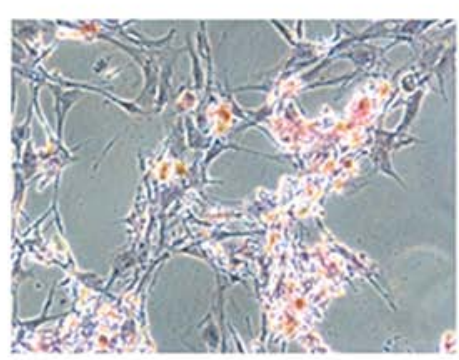

$\mathrm{H}$
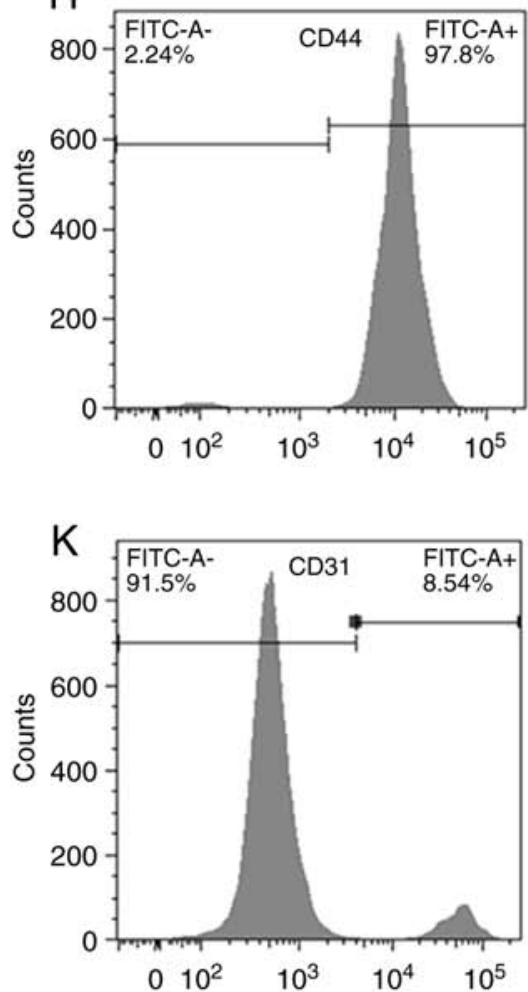

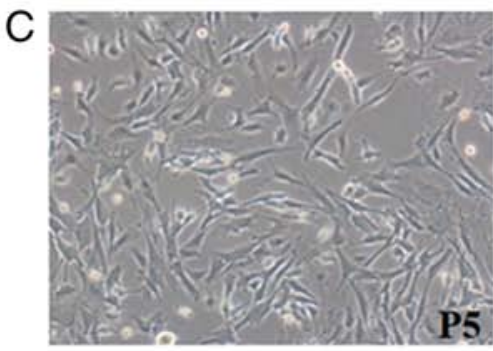

$\mathrm{F}$
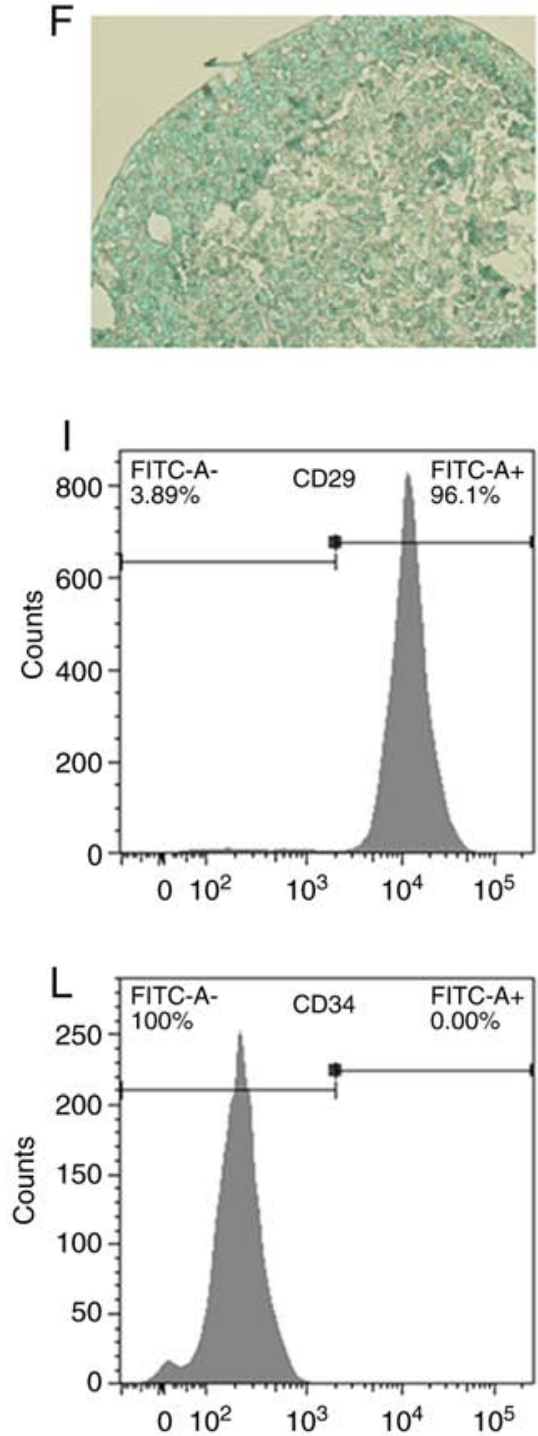

Figure 1. Identification of primary BM-MSCs. Primary BM-MSCs were isolated from the femur and tibia of 4-week-old C57BL/6 mice. (A-C) Morphology of BM-MSCs was observed under light microscopy at P0, P1 and P5 (magnification, x100). (D-F) Differentiation potentials of BM-MSCs into adipocytes, osteoblasts and chondrocytes were confirmed with Oil Red O staining (magnification, x200), Alizarin Red S staining (magnification, x100) and Alcian blue staining (magnification, $\mathrm{x} 400$ ), respectively. (G-L) Flow cytometric detection of surface markers on BM-MSCs. Cells were positive for CD90.2, CD44 and CD29, and negative for CD117, CD31, and CD34. BM-MSCs, bone marrow-derived mesenchymal stromal cells; CD, cluster of differentiation; FITC, fluorescein isothiocyanate; $P$, passage.

can damage AECs; therefore, BLM is used in animal models to replicate pulmonary fibrosis (22). The present study aimed to determine whether BLM stimulation damaged MLE-12 cells. Initially, MLE-12 cells were confirmed to be positive for the pro-SP-C gene (Fig. 2A), which is a specific marker of type II AECs, thus indicating that MLE-12 cells possess characteristics of type II AECs. Subsequently, MLE-12 cells were treated with various concentrations of BLM for $24 \mathrm{~h}$. CCK- 8 assay revealed that BLM significantly decreased the viability of MLE-12 cells at $\geq 1 \mu \mathrm{g} / \mathrm{ml}$ (Fig. 2B). In addition, LDH activity in the supernatants of cultured MLE-12 cells was significantly increased following exposure to 10 and $100 \mu \mathrm{g} / \mathrm{ml} \mathrm{BLM} \mathrm{(Fig.} \mathrm{2C).}$

The protein expression levels of ER stress markers immunoglobulin heavy chain-binding protein (Bip) and X-box 
A

pro-SP-C

DAPI

Merge
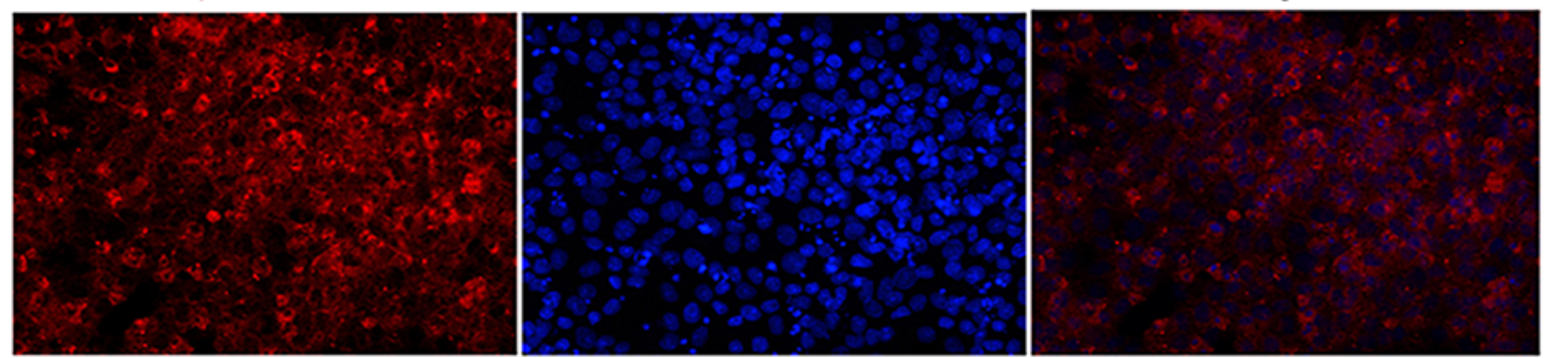

B

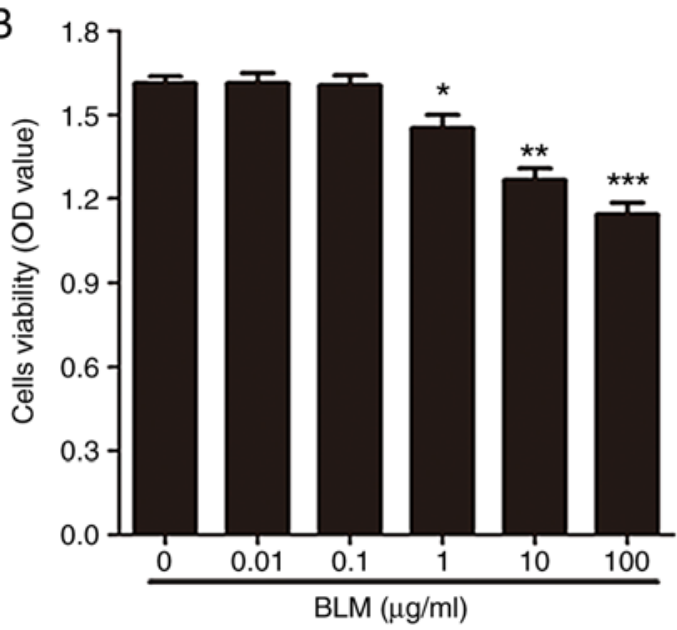

C

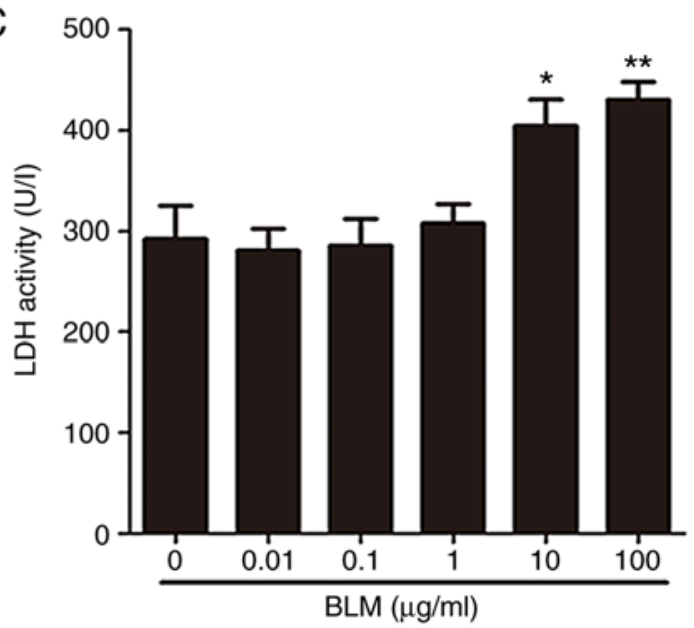

D

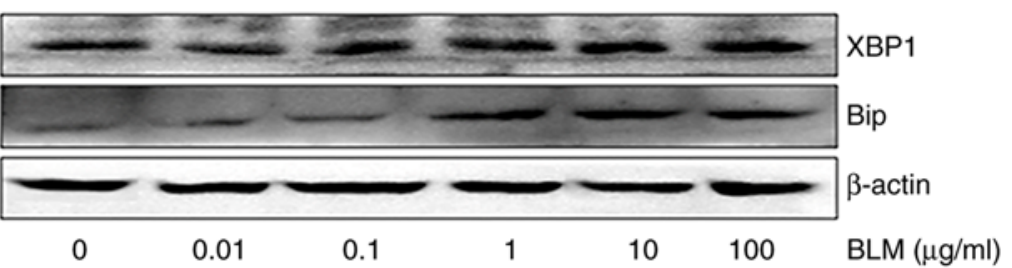

E
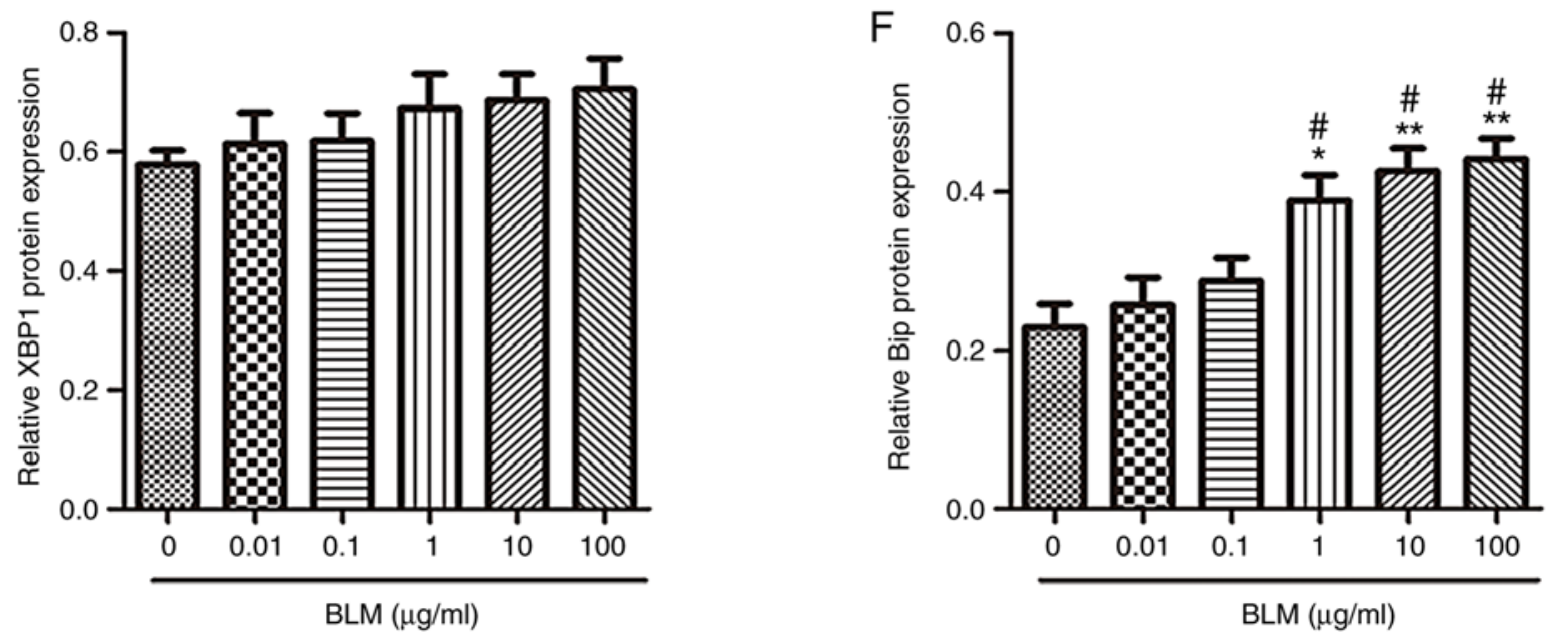

Figure 2. BLM induces endoplasmic reticulum stress in MLE-12 cells. (A) Immunofluorescence staining for pro-SP-C (red) in MLE-12 cells. DAPI (blue) staining was used to detect the nuclei (magnification, x400). (B) Following exposure to the indicated concentrations of BLM for 24 h, the viability of MLE-12 cells was measured by Cell Counting kit-8 assay. (C) Effects of various concentrations of BLM stimulation for $24 \mathrm{~h}$ on LDH activity in the supernatants of MLE-12 cells. (D) Western blot analysis was used to detect the protein expression levels of XBP1 and Bip in MLE-12 cells treated with various concentrations of BLM for $24 \mathrm{~h}$. (E and F) Semi-quantitative analysis of XBP1 and Bip protein expression levels. Data are presented as the means \pm standard error of the mean, $\mathrm{n}=3 .{ }^{*} \mathrm{P}<0.05,{ }^{* *} \mathrm{P}<0.01,{ }^{* * *} \mathrm{P}<0.001$ vs. $0 \mu \mathrm{g} / \mathrm{ml} \mathrm{BLM} ;{ }^{*} \mathrm{P}<0.05$ vs. $0.1 \mu \mathrm{g} / \mathrm{ml}$ BLM. Bip, immunoglobulin heavy chain-binding protein; BLM, bleomycin; LDH, lactate dehydrogenase; MLE, mouse lung epithelial; OD, optical density; XBP1, X-box binding protein 1.

binding protein 1 (XBP1) were then detected in MLE-12 cells following BLM stimulation. Bip is a protein chaperone that assists with protein folding, which is markedly increased with protein accumulation and ER stress (23). XBP1 is a potent transactivator of UPR gene expression, which regulates various cellular functions (24). Following exposure to various 

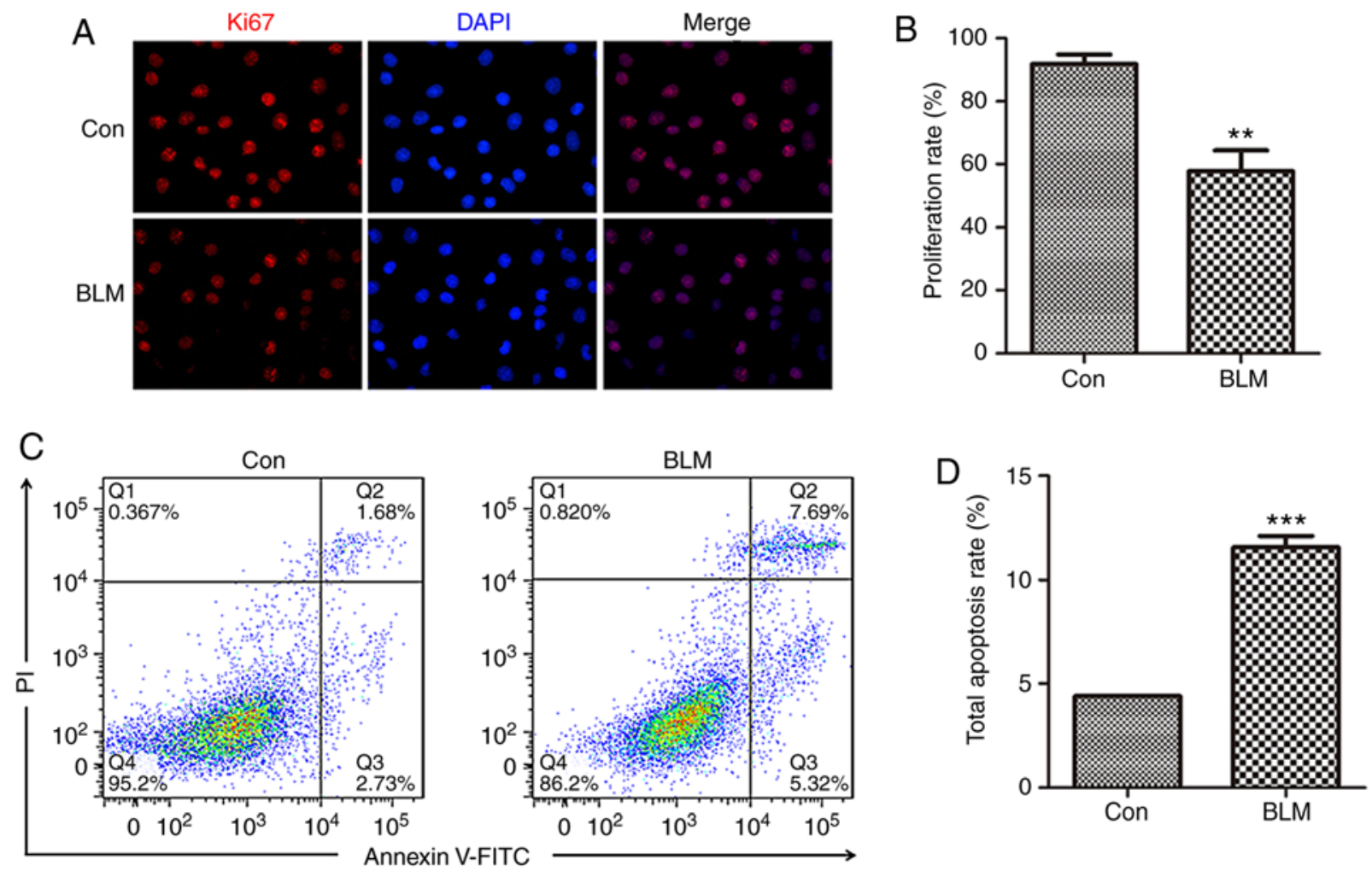

Figure 3. BLM inhibits proliferation and promotes apoptosis of MLE-12 cells. (A) Exposure to $1 \mu \mathrm{g} / \mathrm{ml}$ BLM for $24 \mathrm{~h}$; Ki67 (red) expression was detected in MLE-12 cells by immunofluorescence staining. DAPI (blue) staining was used to detect the nuclei (magnification, x400). (B) Semi-quantitative analysis of Ki67-positive MLE-12 cells. (C) Apoptotic cells were detected by Annexin V-fluorescein isothiocyanate/PI staining and flow cytometry. (D) Quantitative analysis of total apoptotic Annexin $\mathrm{V}^{+} / \mathrm{PI}$ and Annexin $\mathrm{V}^{+} / \mathrm{PI}^{+}$cells is shown. Data are presented as the means \pm standard error of the mean, $\mathrm{n}=3$. ${ }^{* *} \mathrm{P}<0.01$, ${ }_{* * * *} \mathrm{P}<0.001$ vs. Con. BLM, bleomycin; Con, control; MLE, mouse lung epithelial; PI, propidium iodide.
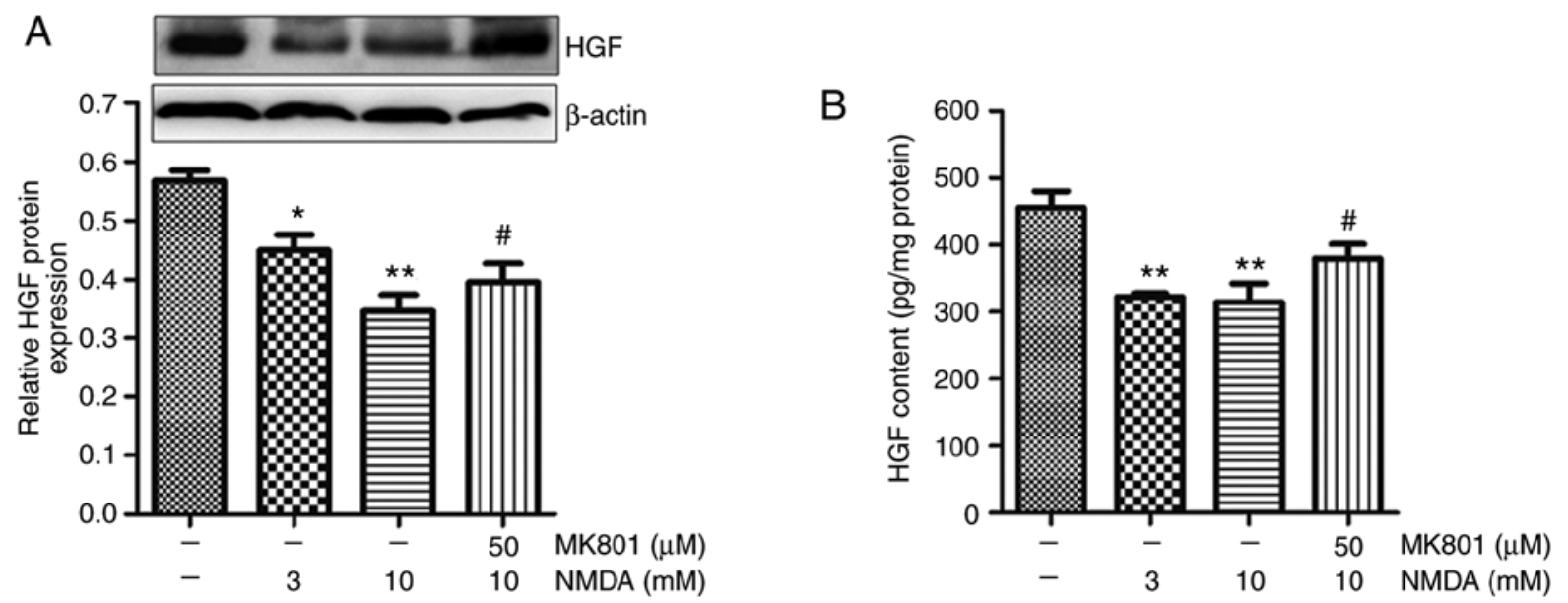

Figure 4. Effects of NMDA receptor activation on HGF expression in BM-MSCs. BM-MSCs were treated with 3 and $10 \mathrm{mM}$ NMDA for $24 \mathrm{~h}$, or were pre-incubated with $50 \mu \mathrm{M}$ MK801 for 30 min prior to $10 \mathrm{mM}$ NMDA treatment. (A) HGF protein expression in BM-MSCs was detected by western blot analysis. (B) ELISA was used to detect HGF secretion in BM-MSCs. Data are presented as the means \pm standard error of the mean, $\mathrm{n}=3$. ${ }^{*} \mathrm{P}<0.05$, ${ }^{* *} \mathrm{P}<0.01 \mathrm{vs}$. control; ${ }^{\#} \mathrm{P}<0.05$ vs. 10 mM NMDA. BM-MSCs, bone marrow-derived mesenchymal stromal cells; HGF, hepatocyte growth factor; NMDA, N-methyl-D-aspartate.

concentrations of BLM for $24 \mathrm{~h}$, although the protein expression levels of XBP1 were not significantly changed, the protein expression levels of Bip were markedly increased in MLE-12 cells in a dose-dependent manner (Fig. 2D-F). These results indicated that BLM stimulation induced ER stress in lung epithelial cells.

ER stress has been reported to promote type II AEC apoptosis $(25,26)$. The present study further examined the proliferation and apoptosis of MLE-12 cells following BLM stimulation. MLE-12 cells were treated with $1 \mu \mathrm{g} / \mathrm{ml}$ BLM for $24 \mathrm{~h}$. Ki67 is a nucleoprotein antigen expressed during cell proliferation, which acts as an index of cell proliferation. To determine cell proliferation status following treatment with BLM, Ki67 expression was measured in MLE-12 cells by immunofluorescence. BLM stimulation significantly reduced the number of Ki67-positive cells (Fig. 3A). The proliferation rate 

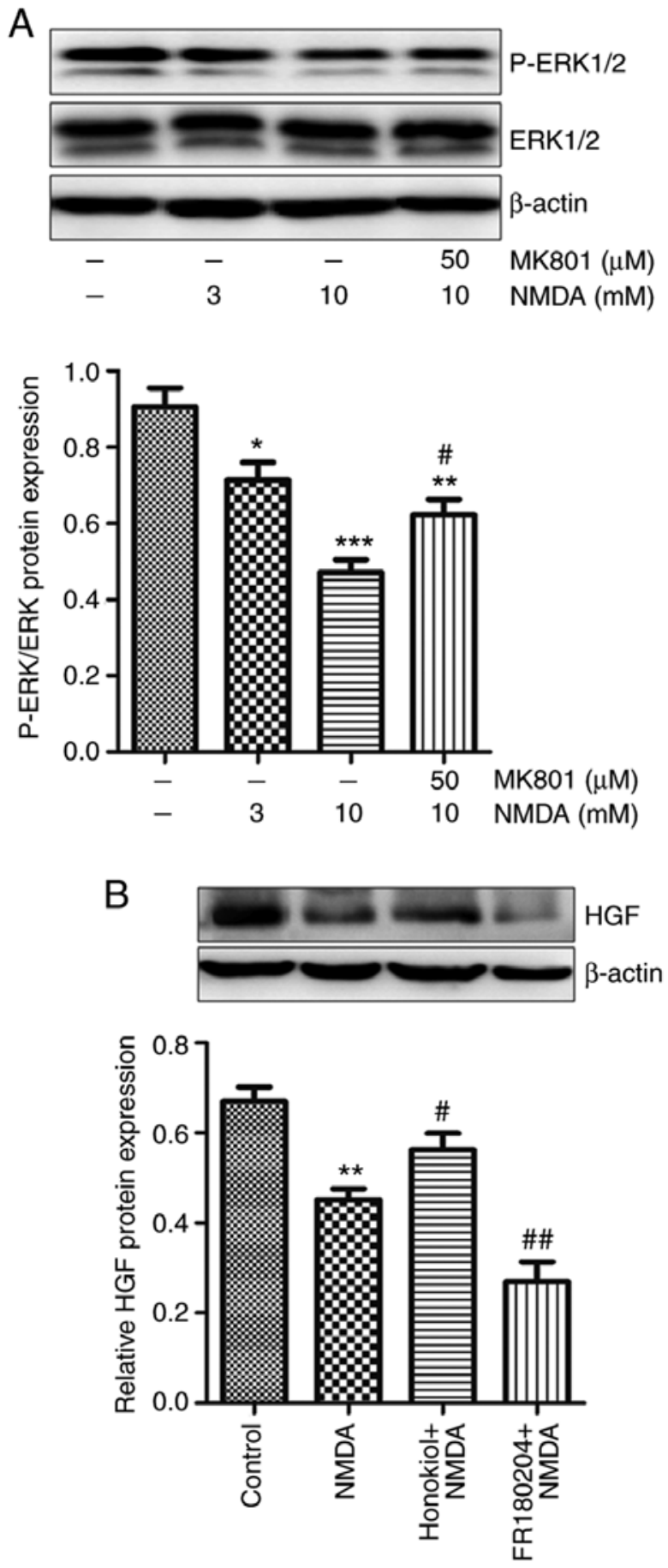
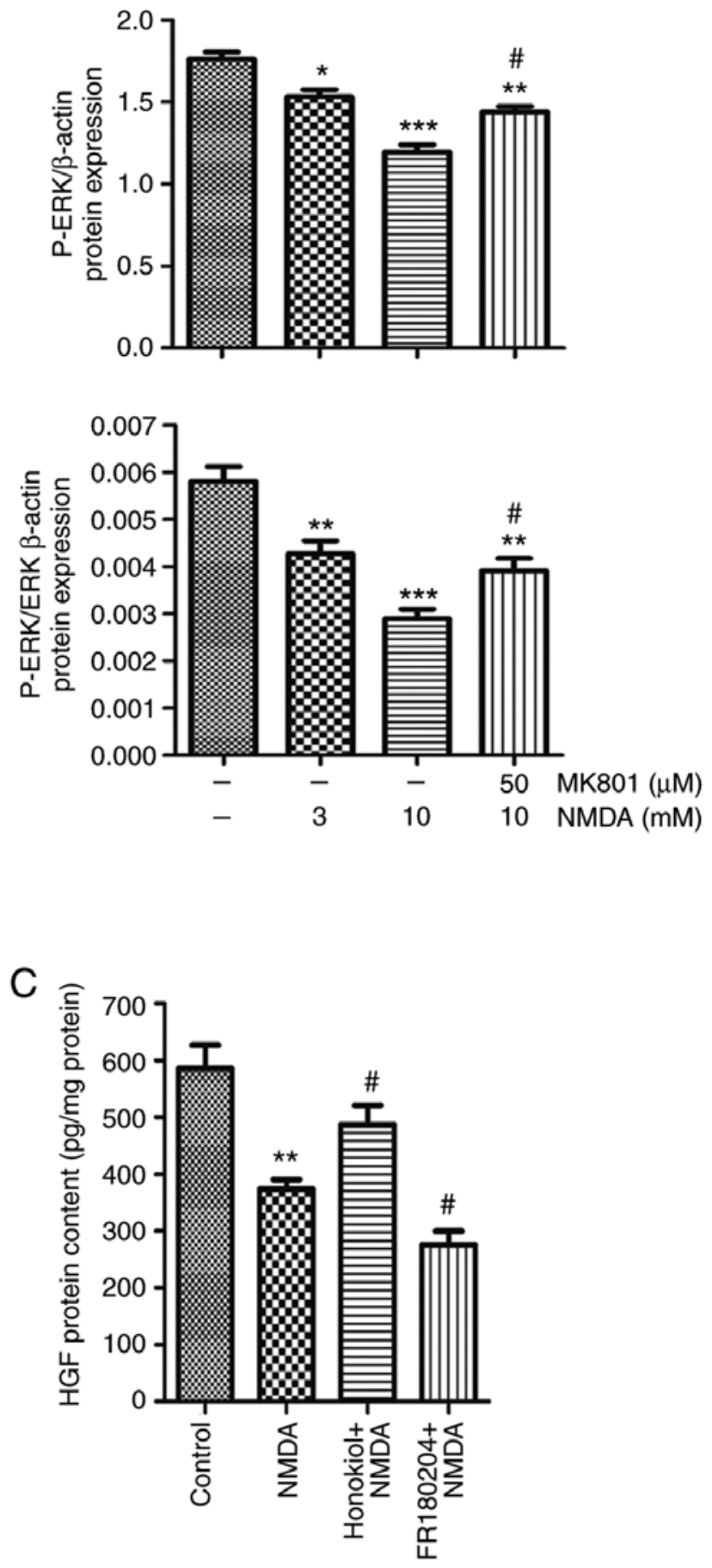

Figure 5. Effects of NMDA receptor activation on ERK signaling in BM-MSCs. (A) BM-MSCs were treated with 3 and $10 \mathrm{mM}$ NMDA for $24 \mathrm{~h}$, or were pre-incubated with $50 \mu \mathrm{M}$ MK801 for $30 \mathrm{~min}$ prior to $10 \mathrm{mM}$ NMDA treatment. Protein expression levels of P-ERK1/2 and ERK1/2 were detected in BM-MSCs by western blotting. Data are presented as the means \pm standard error of the mean, $n=3 .{ }^{*} \mathrm{P}<0.05,{ }^{* *} \mathrm{P}<0.01,{ }^{* * * *} \mathrm{P}<0.001 \mathrm{vs}$. control; ${ }^{*} \mathrm{P}<0.05$ vs. $10 \mathrm{mM}$ NMDA. (B and C) BM-MSCs were treated with $10 \mu \mathrm{M}$ Honokiol (ERK1/2 activator) or FR180204 (ERK1/2 inhibitor), for 30 min prior to treatment with $3 \mathrm{mM}$ NMDA for $24 \mathrm{~h}$. HGF protein expression and secretion in BM-MSCs was detected by western blotting and ELISA, respectively. Data are presented as the means \pm standard error of the mean, $\mathrm{n}=3 .{ }^{* *} \mathrm{P}<0.01$ vs. control; ${ }^{*} \mathrm{P}<0.05,{ }^{\# \# /} \mathrm{P}<0.01 \mathrm{vs}$. NMDA. BM-MSCs, bone marrow-derived mesenchymal stromal cells; ERK, extracellular signal-regulated kinase; HGF, hepatocyte growth factor; NMDA, N-methyl-D-aspartate; P-, phosphorylated.

was calculated by counting the number of Ki67-positive cells in all groups (Fig. 3B). Subsequently, following BLM treatment, apoptosis of MLE-12 cells was detected by flow cytometry (Fig. 3C). The results revealed that BLM significantly promoted MLE-12 cell apoptosis (Fig. 3D). These findings suggested that BLM induced AEC damage, by inducing ER stress, inhibiting cell proliferation and promoting cell apoptosis.
NMDA receptor activation downregulates HGF in BM-MSCs through the mitogen-activated protein kinase (MAPK)/ERK signaling pathway. Our previous study revealed that NMDA receptor activation selectively decreases the secretion of HGF in BM-MSCs, and NMDA pretreatment weakens the protective effects of BM-MSCs on BLM-induced pulmonary fibrosis (19). The protein expression levels and secretion of 

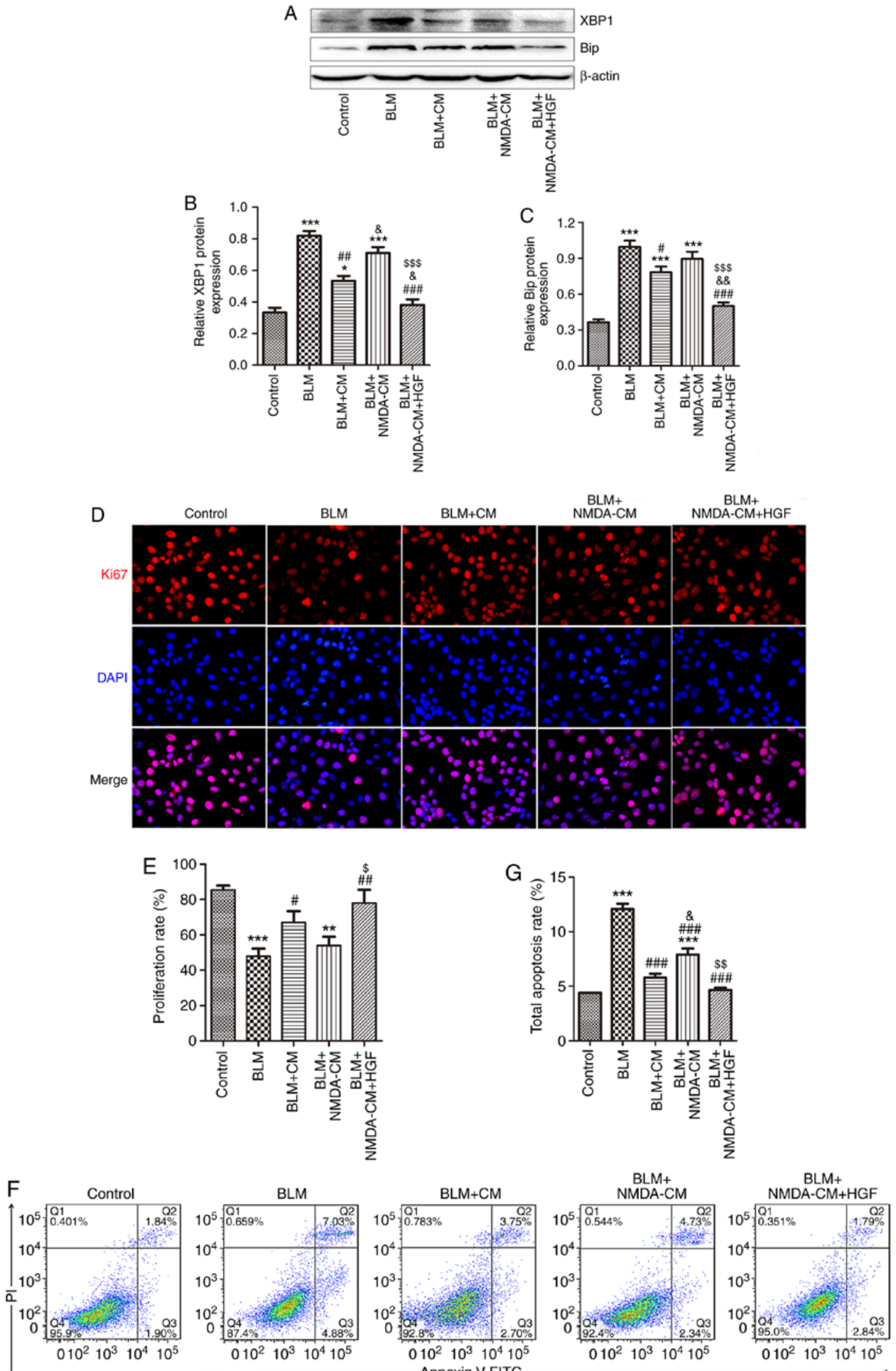

Figure 6. Effects of NMDA-CM on BLM-treated MLE-12 cells. Normal or $3 \mathrm{mM}$ NMDA-CM was used to co-culture $1 \mu \mathrm{g} / \mathrm{ml}$ BLM-treated MLE-12 cells for $24 \mathrm{~h}$. Furthermore, $10 \mathrm{ng} / \mathrm{ml} \mathrm{HGF}$ was simultaneously used to treat MLE-12 cells. (A) Protein expression levels of XBP1 and Bip in MLE-12 cells were measured by western blotting. (B and C) Semi-quantitative analysis of XBP1 and Bip protein expression levels. (D) Immunofluorescence staining of Ki67 (red) in MLE-12 cells. DAPI (blue) staining was used to detect the nuclei (magnification, x400). (E) Semi-quantitative analysis of Ki67-positive MLE-12 cells. (F) Apoptotic cells were identified by Annexin V-fluorescein isothiocyanate/PI staining by flow cytometry. (G) Quantitative analysis of total apoptotic Annexin $\mathrm{V}^{+} / \mathrm{PI}^{-}$and Annexin $\mathrm{V}^{+} / \mathrm{PI}^{+}$cells is shown. Data are presented as the means \pm standard error of the mean, $\mathrm{n}=3$. ${ }^{*} \mathrm{P}<0.05,{ }^{* *} \mathrm{P}<0.01,{ }^{* * * *} \mathrm{P}<0.001 \mathrm{vs}$. control; ${ }^{\#} \mathrm{P}<0.05,{ }^{\# \#} \mathrm{P}<0.01,{ }^{\# \# \#} \mathrm{P}<0.001$ vs. BLM, ${ }^{\&} \mathrm{P}<0.05,{ }^{\& \&} \mathrm{P}<0.01$ vs. BLM $+\mathrm{CM},{ }^{\$} \mathrm{P}<0.05,{ }^{\mathrm{S}} \mathrm{P}<0.01,{ }^{\$ \$ \$} \mathrm{P}<0.001$ vs. BLM + NMDA-CM. Bip, immunoglobulin heavy chain-binding protein; BLM, bleomycin; CM, conditioned medium; HGF, hepatocyte growth factor; MSC-CM; mesenchymal stromal cell-derived CM; NMDA-CM, NMDA-preconditioned MSC-CM; NMDA, N-methyl-D-aspartate; PI, propidium iodide; XBP1, X-box binding protein 1. 
HGF in BM-MSCs and their supernatants were measured by western blotting and ELISA, respectively. NMDA is a synthetic agonist that selectively activates the NMDA receptor, whereas MK801 is a noncompetitive channel antagonist of the NMDA receptor. The results indicated that the synthesis and secretion of HGF were downregulated in response to 3 and $10 \mathrm{mM}$ NMDA in BM-MSCs (Fig. 4). Conversely, $50 \mu \mathrm{M}$ MK801 partially eliminated the reduction in $\mathrm{HGF}$ caused by $10 \mathrm{mM}$ NMDA (Fig. 4).

ERK is a MAPK signaling molecule. Alterations in the phosphorylation of ERK can reflect the activity of certain transcription factors. The present results demonstrated that the phosphorylation levels of ERK1/2 (Thr202/204) were decreased following treatment with 3 and $10 \mathrm{mM}$ NMDA in BM-MSCs (Fig. 5A). Furthermore, $50 \mu \mathrm{M}$ MK801 partially relieved the decrease in ERK phosphorylation caused by $10 \mathrm{mM}$ NMDA in BM-MSCs (Fig. 5A). To confirm the role of MAPK/ERK signaling in the decrease of HGF in BM-MSCs caused by NMDA receptor activation, the ERK inhibitor, FR180204, and the ERK activator, Honokiol, were used to treat BM-MSCs during NMDA treatment. The results demonstrated that $10 \mu \mathrm{M}$ Honokiol partially eliminated the decrease in HGF expression, whereas $10 \mu \mathrm{M}$ FR180204 further promoted the reduction in HGF caused by NMDA (Fig. 5B and C). Taken together, these results suggested that NMDA receptor activation may downregulate HGF by inhibiting MAPK/ERK signaling in BM-MSCs.

MSC-CM attenuates BLM-induced ER stress, promotes proliferation and inhibits apoptosis of MLE-12 cells. To observe the effect of BM-MSCs on BLM-induced AEC injury, MSC-CM was prepared to co-culture BM-MSCs and MLE-12 cells. The results revealed that the protein expression levels of ER stress markers XBP1 and Bip were markedly elevated in MLE-12 cells in response to $1 \mu \mathrm{g} / \mathrm{ml}$ BLM stimulation compared with in the control group. However, the upregulation of XBP1 and Bip was abolished by MSC-CM treatment (Fig. 6A-C). In addition, Ki67 expression and apoptosis rate was detected in MLE-12 cells following MSC-CM treatment. The results demonstrated that cell proliferation was partially upregulated, and cell apoptosis was partially reduced following treatment with MSC-CM compared with in the BLM group (Fig. 6D-G). These findings suggested that MSC-CM may attenuate BLM-induced injury in lung epithelial cells via paracrine effects.

NMDA-preconditioned MSC-CM cannot protect MLE-12 cells from BLM-induced injury by downregulating HGF. HGF secreted by BM-MSCs has been reported to reduce ER stress and improve repair in type II AECs (27). The reduction in lung epithelial cell apoptosis and the increase in cell proliferation induced by MSC-CM depends on HGF signaling (28). In the present study, $3 \mathrm{mM}$ NMDA was used to pretreat BM-MSCs prior to the generation of MSC-CM. As shown in Fig. 6A-C, the protein expression levels of ER stress markers XBP1 and Bip were not significantly decreased in MLE-12 cells in the NMDA-preconditioned MSC-CM treatment group compared with in the BLM group; however, XBP1 expression was significantly increased compared with in the normal MSC-CM treatment group. The proliferation of MLE-12 cells in the NMDA-preconditioned MSC-CM and HGF treatment group was significantly higher compared with in the NMDA-preconditioned MSC-CM treatment group (Fig. 6D and E). Furthermore, the total apoptosis rate of MLE-12 cells in the NMDA-preconditioned MSC-CM and HGF treatment group was lower compared with in the NMDA-preconditioned MSC-CM treatment group (Fig. 6F). These results indicated that NMDA-preconditioned MSC-CM did not protect AECs from BLM-induced damage; NMDA receptor activation inhibited the protective effects of MSC-CM on BLM-induced injury in AECs.

The present study also conducted a rescue experiment to verify the role of NMDA receptor activation-induced HGF downregulation. BLM-stimulated MLE-12 cells were simultaneously treated with recombinant $\mathrm{HGF}(10 \mathrm{ng} / \mathrm{ml})$ alongside or NMDA-preconditioned MSC-CM. Notably, the protein expression levels of XBP1 and Bip were markedly decreased in MLE-12 cells following recombinant HGF treatment compared with in the NMDA-preconditioned MSC-CM treatment group (Fig. 6A-C). The proliferation rate was also significantly increased (Fig. 6D and E), whereas the total apoptosis rate was decreased (Fig. 6F) in MLE-12 cells in the HGF treatment group compared with in the NMDA-preconditioned MSC-CM treatment group. These findings indicated that recombinant HGF treatment may reverse the inhibitory effect of NMDA receptor activation on the protective activity of MSC-CM on BLM-induced injury in AECs. Taken together, NMDA receptor activation inhibited the protective effect of MSC-CM on BLM-induced injury in lung epithelial cells by decreasing HGF.

\section{Discussion}

BLM is one of the most extensively studied drugs for the generation of reproducible models of lung fibrosis in mice (28). When BLM is administered into the airways, it induces lung epithelial cell death, followed by acute neutrophilic influx, chronic inflammation and parenchymal fibrosis within 4 weeks of administration to susceptible strains of mice (29). The present study proposed that BLM stimulation may induce ER stress, promote apoptosis and inhibit proliferation of MLE-12 cells in vitro. Previous studies have reported that BLM also induces apoptosis of primary AECs (30) and MLE-15 cells (31). Therefore, BLM may lead to lung epithelial cell dysfunction, which is an important cause of BLM-induced pulmonary fibrosis.

ER stress has been detected in AECs from the lungs of patients with IPF and from mice following BLM challenge $(4,5)$. Zhong et al revealed that ER stress caused by chemical induction and overexpression of mutant pro-SP-C leads to EMT in AECs in vitro (5). Expression of mutant L188Q pro-SP-C in vivo can also lead to ER stress in type II AECs in mice. Following intratracheal administration of BLM, L188Q pro-SP-C-expressing mice develop exaggerated lung fibrosis, increased apoptosis of AECs and marked numbers of fibroblasts in the lungs (6). Zhao et al demonstrated that Bip/GRP78, activating transcription factor 6 , eukaryotic translation initiation factor $2 \mathrm{~A}$ and XBP1, which are signaling molecules of ER stress, are elevated in the lungs of mice with BLM-induced pulmonary fibrosis (8). Furthermore, 
the markers of ER stress have been colocalized in AECs with markers of apoptosis in sporadic IPF (32). Therefore, ER stress and UPR activation may be considered important factors in AEC apoptosis and dysfunction in IPF, and may be involved in the pathogenesis of pulmonary fibrosis. The majority of previous studies used the expression of mutant pro-SP-C or chemical reagents in AECs to induce ER stress in vitro, or L188Q pro-SP-C-expressing mice in type II AECs to investigate the role of ER stress in pulmonary fibrosis in vivo $(5,6,25)$. In previous studies, it was revealed that A549 and MLE-12 cells transfected with L188Q pro-SP-C exhibit a greater number of apoptotic cells compared with untransfected or wild type pro-SP-C-transfected cells. In the present study, the protein expression levels of ER stress markers Bip and XBP1 were significantly increased following direct stimulation of MLE-12 cells with BLM, thus indicating that BLM stimulation may induce ER stress in lung epithelial cells. Furthermore, the apoptosis rate of MLE-12 cells was increased, and the amount of Ki67-positive proliferating cells was decreased, suggesting that the lung epithelial cells were damaged by BLM stimulation.

BM-MSCs can home to BLM-injured lungs and differentiate into AECs, in order to achieve antifibrotic benefits following intravenous administration in an animal model of pulmonary fibrosis $(13,33)$. A previous study reported that BM-MSCs mediate their protective effect by releasing paracrine factors to regulate the microenvironment and repair damaged tissues (34). Furthermore, Shen et al used MSC-CM to protect rats from BLM-induced lung injury and fibrosis in vivo, and human non-small cell lung cancer epithelial A549 cells from BLM-induced apoptosis in vitro (35). In the present study, it was demonstrated that MSC-CM protected MLE-12 cells from BLM-induced damage; notably, MSC-CM eliminated the increase in Bip and XBP1 protein expression and apoptosis rate, and the decrease in proliferation rate caused by BLM. Therefore, this study provided further evidence supporting the role of the paracrine effects of BM-MSCs on improving BLM-induced lung epithelial damage. Among the paracrine factors secreted by MSCs, HGF, a pleiotropic growth factor, serves an important role in lung development, inflammation, repair and regeneration (36). Cahill et al demonstrated that MSC-CM enhances wound healing and epithelial proliferation, and also reduces epithelial cell apoptosis depending on HGF in vitro, whereas MSCs with HGF knockdown are unable to protect against fibrosis in vivo (28).

The NMDA receptor is an important excitatory amino acid receptor in the central nervous system. The NMDA receptor is also present in non-neurological tissues and cells, and its role in these tissues and cells has received much recent attention. Our group has been working to study the role of NMDA receptor activation in lung tissue. Numerous studies have demonstrated that endogenous glutamate release and NMDA receptor activation serve important roles in different models of lung injury and fibrosis (37-40). Our recent study revealed that the functional NMDA receptor is present in BM-MSCs, and NMDA receptor activation downregulates HGF secretion in BM-MSCs, thus eliminating the inhibitory effects of BM-MSCs on EMT and fibroblast activation (19). In vivo experiments confirmed that intravenous injection of NMDA-preconditioned BM-MSCs does not effectively protect against BLM-induced pulmonary fibrosis (19). In the present study, it was further verified that NMDA receptor activation decreased HGF synthesis and secretion, as determined by western blotting and ELISA. Notably, this study demonstrated that NMDA-preconditioned MSC-CM did not effectively protect against BLM-induced MLE-12 cell damage in vitro. Rescue experiments with recombinant HGF partially eliminated the reduced protective effect of BM-MSCs induced by NMDA pretreatment, thus suggesting that HGF downregulation may be involved in the attenuation of the protective effect of BM-MSCs induced by NMDA receptor activation.

To investigate the signaling pathways by which NMDA receptor activation inhibits HGF synthesis and secretion, the present study investigated alterations in ERK phosphorylation. After activating and inhibiting the ERK signaling pathway by Honokiol and FR180204, respectively, alterations in the protein expression and secretion of HGF in BM-MSCs were detected. Honokiol, an ERK activator, was able to reverse the decrease in HGF expression and secretion caused by NMDA. Conversely, FR180204, an ERK inhibitor, further decreased HGF expression and secretion. Therefore, the downregulation of the ERK signaling pathway may be involved in NMDA-induced decrease of HGF expression and secretion.

In conclusion, the present study demonstrated that NMDA receptor activation downregulated HGF synthesis and secretion by inhibiting MAPK/ERK signaling, thus impairing the protective effect of BM-MSCs on BLM-induced AEC injury. These results may explain our previous finding that NMDA receptor activation eliminates the beneficial effects of BM-MSCs on BLM-induced pulmonary fibrosis (19). Furthermore, our other previous study revealed that an NMDA receptor antagonist can reduce lung injury caused by intratracheal injection of BLM (37). Therefore, systemic administration of NMDA receptor antagonists may protect mice from BLM-induced pulmonary fibrosis and even patients with pulmonary fibrosis.

\section{Acknowledgements}

Not applicable.

\section{Funding}

This study was supported by the National Natural Science Foundation of China (grant no. 81570065).

\section{Availability of data and materials}

All data generated or analyzed during this study are included in this published article.

\section{Authors' contributions}

$\mathrm{XP}$ and XL performed experiments and wrote the manuscript. $\mathrm{CL}, \mathrm{SY}$ and YH performed experiments. $\mathrm{PH}, \mathrm{HC}$ and $\mathrm{YZ}$ performed analysis and interpretation of data. YT and WL analyzed data and edited the manuscript. ZL and DF designed and organized the study, analyzed the data and edited the 
manuscript. All authors read and approved the final, submitted version of the manuscript.

\section{Ethics approval and consent to participate}

All animal experiments were approved by the Ethics Committee of the Institute of Clinical Pharmacology at Central South University, and were strictly performed in accordance with the guidelines of the National Institutes of Health.

\section{Patient consent for publication}

Not applicable.

\section{Competing interests}

The authors declare that they have no competing interests.

\section{References}

1. Li X, Yue S and Luo Z: Mesenchymal stem cells in idiopathic pulmonary fibrosis. Oncotarget 8: 102600-102616, 2017.

2. Liu YM, Nepali K and Liou JP: Idiopathic pulmonary fibrosis: Current status, recent progress, and emerging targets. J Med Chem 60: 527-553, 2017.

3. Knudsen L, Ruppert $\mathrm{C}$ and Ochs M: Tissue remodelling in pulmonary fibrosis. Cell Tissue Res 367: 607-626, 2017.

4. Adamson IY, Young L and Bowden DH: Relationship of alveolar epithelial injury and repair to the induction of pulmonary fibrosis. Am J Pathol 130: 377-383, 1988

5. Lawson WE, Crossno PF, Polosukhin VV, Roldan J, Cheng DS, Lane KB, Blackwell TR, Xu C, Markin C, Ware LB, et al: Endoplasmic reticulum stress in alveolar epithelial cells is prominent in IPF: Association with altered surfactant protein processing and herpesvirus infection. Am J Physiol Lung Cell Mol Physiol 294: L1119-L1126, 2008.

6. Zhong Q, Zhou B, Ann DK, Minoo P, Liu Y, Banfalvi A, Krishnaveni MS, Dubourd M, Demaio L, Willis BC, et al: Role of endoplasmic reticulum stress in epithelial-mesenchymal transition of alveolar epithelial cells: Effects of misfolded surfactant protein. Am J Respir Cell Mol Biol 45: 498-509, 2011.

7. Lawson WE, Cheng DS, Degryse AL, Tanjore H, Polosukhin VV, $\mathrm{Xu} X \mathrm{X}, \mathrm{Newcomb} \mathrm{DC}$, Jones BR, Roldan J, Lane KB, et al: Endoplasmic reticulum stress enhances fibrotic remodeling in the lungs. Proc Natl Acad Sci USA 108: 10562-10567, 2011.

8. Zhao H, Wu QQ, Cao LF, Qing HY, Zhang C, Chen YH, Wang H, Liu RY and Xu DX: Melatonin inhibits endoplasmic reticulum stress and epithelial-mesenchymal transition during bleomycin-induced pulmonary fibrosis in mice. PLoS One 9: e97266, 2014.

9. Wu J and Kaufman RJ: From acute ER stress to physiological roles of the unfolded protein response. Cell Death Differ 13: 374-384, 2006.

10. Chakrabarti A, Chen AW and Varner JD: A review of the mammalian unfolded protein response. Biotechnol Bioeng 108: 2777-2793, 2011

11. Ghadiri M, Young PM and Traini D: Cell-based therapies for the treatment of idiopathic pulmonary fibrosis (IPF) disease. Expert Opin Biol Ther 16: 375-387, 2016.

12. Sinclair K, Yerkovich ST and Chambers DC: Mesenchymal stem cells and the lung. Respirology 18: 397-411, 2013.

13. Antunes MA, Laffey JG, Pelosi P and Rocco PR: Mesenchymal stem cell trials for pulmonary diseases. J Cell Biochem 115: 1023-1032, 2014.

14. Ortiz LA, Gambelli F, McBride C, Gaupp D, Baddoo M, Kaminski $\mathrm{N}$ and Phinney DG: Mesenchymal stem cell engraftment in lung is enhanced in response to bleomycin exposure and ameliorates its fibrotic effects. Proc Natl Acad Sci USA 100: 8407-8411, 2003.

15. Hu S, Li J, Xu X, Liu A, He H, Xu J, Chen Q, Liu S, Liu L, Qiu H and Yang Y: The hepatocyte growth factor-expressing character is required for mesenchymal stem cells to protect the lung injured by lipopolysaccharide in vivo. Stem Cell Res Ther 7: 66, 2016.
16. Dong LH, Jiang YY, Liu YJ, Cui S, Xia CC, Qu C, Jiang X, Qu YQ, Chang PY and Liu F: The anti-fibrotic effects of mesenchymal stem cells on irradiated lungs via stimulating endogenous secretion of HGF and PGE2. Sci Rep 5: 8713, 2015.

17. Kumar A: NMDA receptor function during senescence: Implication on cognitive performance. Front Neurosci 9: 473, 2015.

18. Griffin WR III, Haun HL, Hazelbaker CL, Ramachandra VS and Becker HC: Increased extracellular glutamate in the nucleus accumbens promotes excessive ethanol drinking in ethanol dependent mice. Neuropsychopharmacology 39: 707-717, 2014.

19. Li X, Li C, Tang Y, Huang Y, Cheng Q, Huang X, Zhao F, Hao C, Feng D, Xu J, et al: NMDA receptor activation inhibits the antifibrotic effect of BM-MSCs on bleomycin-induced pulmonary fibrosis. Am J Physiol Lung Cell Mol Physiol 315: L404-L421, 2018.

20. Xu S, De Becker A, Van Camp B, Vanderkerken K and Van Riet I: An improved harvest and in vitro expansion protocol for murine bone marrow-derived mesenchymal stem cells. J Biomed Biotechnol 2010: 105940, 2010.

21. Dominici M, Le Blanc K, Mueller I, Slaper-Cortenbach I, Marini F, Krause D, Deans R, Keating A, Prockop Dj and Horwitz E: Minimal criteria for defining multipotent mesenchymal stromal cells. The International Society for Cellular Therapy position statement. Cytotherapy 8: 315-317, 2006.

22. Della Latta V, Cecchettini A, Del RS and Morales MA: Bleomycin in the setting of lung fibrosis induction: From biological mechanisms to counteractions. Pharmacol Res 97: 122-130, 2015.

23. Schroder M and Kaufman RJ: The mammalian unfolded protein response. Annu Rev Biochem 74: 739-789, 2005.

24. Yoshida H, Matsui T, Yamamoto A, Okada T and Mori K: XBP1 mRNA is induced by ATF6 and spliced by IRE1 in response to ER stress to produce a highly active transcription factor. Cell 107: 881-891, 2001.

25. Mulugeta S, Nguyen V, Russo SJ, Muniswamy M and Beers MF: A surfactant protein $\mathrm{C}$ precursor protein BRICHOS domain mutation causes endoplasmic reticulum stress, proteasome dysfunction, and caspase 3 activation. Am J Respir Cell Mol Biol 32: 521-530, 2005.

26. Mulugeta S, Maguire JA, Newitt JL, Russo SJ, Kotorashvili A and Beers MF: Misfolded BRICHOS SP-C mutant proteins induce apoptosis via caspase-4- and cytochrome c-related mechanisms. Am J Physiol Lung Cell Mol Physiol 293: L720-L729, 2007.

27. Nita I, Hostettler K, Tamo L, Medová M, Bombaci G, Zhong J, Allam R, Zimmer Y, Roth M, Geiser T and Gazdhar A: Hepatocyte growth factor secreted by bone marrow stem cell reduce ER stress and improves repair in alveolar epithelial II cells. Sci Rep 7: 41901, 2017.

28. Cahill EF, Kennelly H, Carty F, Mahon BP and English K: Hepatocyte growth factor is required for mesenchymal stromal cell protection against bleomycin-induced pulmonary fibrosis. Stem Cells Transl Med 5: 1307-1318, 2016.

29. Schrier DJ, Kunkel RG and Phan SH: The role of strain variation in murine bleomycin-induced pulmonary fibrosis. Am Rev Respir Dis 127: 63-66, 1983.

30. Wang R, Ibarra-Sunga O, Verlinski L, Pick R and Uhal BD: Abrogation of bleomycin-induced epithelial apoptosis and lung fibrosis by captopril or by a caspase inhibitor. Am J Physiol Lung Cell Mol Physiol 279: L143-L151, 2000.

31. Wallach-Dayan SB, Izbicki G, Cohen PY, Gerstl-Golan R, Fine A and Breuer R: Bleomycin initiates apoptosis of lung epithelial cells by ROS but not by Fas/FasL pathway. Am J Physiol Lung Cell Mol Physiol 290: L790-L796, 2006.

32. Korfei M, Ruppert C, Mahavadi P, Henneke I, Markart P, Koch M, Lang G, Fink L, Bohle RM, Seeger W, et al: Epithelial endoplasmic reticulum stress and apoptosis in sporadic idiopathic pulmonary fibrosis. Am J Respir Crit Care Med 178: 838-846, 2008.

33. Gao J, Dennis JE, Muzic RF, Lundberg M and Caplan AI: The dynamic in vivo distribution of bone marrow-derived mesenchymal stem cells after infusion. Cells Tissues Organs 169: $12-20,2001$.

34. Rojas M, Xu J, Woods CR, Mora AL, Spears W, Roman J and Brigham KL: Bone marrow-derived mesenchymal stem cells in repair of the injured lung. Am J Respir Cell Mol Biol 33: 145-152, 2005.

35. Shen Q, Chen B, Xiao Z, Zhao L, Xu X, Wan X, Jin M, Dai J and Dai H: Paracrine factors from mesenchymal stem cells attenuate epithelial injury and lung fibrosis. Mol Med Rep 11: 2831-2837, 2015. 
36. Seedorf G, Metoxen AJ, Rock R, Markham N, Ryan S, Vu T and Abman SH: Hepatocyte growth factor as a downstream mediator of vascular endothelial growth factor-dependent preservation of growth in the developing lung. Am J Physiol Lung Cell Mol Physiol 310: L1098-L1110, 2016.

37. Li Y, Liu Y, Peng X, Liu W, Zhao F, Feng D, Han J, Huang Y, Luo $\mathrm{S}, \mathrm{Li} \mathrm{L}$, et al: NMDA receptor antagonist attenuates bleomycin-induced acute lung injury. PLoS One 10: e125873, 2015.

38. Shang LH, Luo ZQ, Deng XD, Wang MJ, Huang FR, Feng DD and Yue SJ: Expression of N-methyl-D-aspartate receptor and its effect on nitric oxide production of rat alveolar macrophages. Nitric Oxide 23: 327-331, 2010.
39. Tang F, Yue S, Luo Z, Feng D, Wang M, Qian C, Zhen X and Duan Y: Role of N-methyl-D-aspartate receptor in hyperoxiainduced lung injury. Pediatr Pulmonol 40: 437-444, 2005.

40. Wang M, Luo Z, Liu S, Li L, Deng X, Huang F, Shang L, Jian C and Yue S: Glutamate mediates hyperoxia-induced newborn rat lung injury through $\mathrm{N}$-methyl-D-aspartate receptors. Am J Respir Cell Mol Biol 40: 260-267, 2009.

(i) This work is licensed under a Creative Commons cc) $\mathrm{EY}$ NO ND Attribution-NonCommercial-NoDerivatives 4.0 International (CC BY-NC-ND 4.0) License. 